\title{
Now we are 30: 10 more years of MASCC
}

\author{
Ian N. Olver ${ }^{1}$ (I) $\cdot$ Melissa Chin ${ }^{2} \cdot$ Rajesh V. Lalla $^{3}$
}

Received: 21 December 2020 / Accepted: 12 January 2021 / Published online: 23 January 2021

(C) The Author(s), under exclusive licence to Springer-Verlag GmbH, DE part of Springer Nature 2021

\begin{abstract}
This paper chronicles the third decade of MASCC from 2010. There was a generational change in this decade, building on the solid foundation of the founders. It included the first female President, and a new Executive Director with a background in strategy and business development and operations as applied to healthcare. The headquarters moved from Copenhagen to Toronto. The first meeting to be held outside of Europe or North America was held in Adelaide, Australia, and the membership in the Asia Pacific region expanded. A program of international affiliates saw national supportive care organisations formally link with MASCC. In cancer supportive care, there was a raft of new toxicities to manage as immunotherapies were added to conventional cytotoxic treatment. There was also a greater emphasis on the psychosocial needs of patients and families. New MASCC groups were formed to respond to this evolution in cancer management. The MASCC journal, Supportive Care in Cancer, continued to grow in impact, and MASCC published two editions of a textbook of supportive care and survivorship. The decade ended with the challenge of the COVID-19 pandemic, but that served to highlight the importance of good supportive care to patients with cancer.
\end{abstract}

Keywords Multinational Association of Supportive Care in cancer (MASCC) · History $\cdot$ Study groups $\cdot$ Third decade

\section{Introduction}

In 2010, Cindy Rittenberg and colleagues published the oral history of MASCC (Multinational Association of Supportive Care in Cancer) from its incorporation in 1990 and its first meeting as MASCC in 1992 [1]. It was written from the experiences of the founders and leaders of that time. The next 10 years from 2010 can be characterised as encompassing a generational change as new leaders built upon that foundation.

MASCC with ISOO (International Society of Oral Oncology) continued to grow and expand its international presence. It began to develop the flexibility that was necessary in a changing external environment by creating new study groups and publishing guidelines in emerging areas of

Ian N. Olver

Ian.olver@adelaide.edu.au

1 School of Psychology, Division of Health and Medical Sciences, University of Adelaide, Room 721A Hughes Building, North Terrace, Adelaide, South Australia 5005, Australia

2 Multinational Association of Supportive Care in Cancer, Toronto, Canada

3 School of Dental Medicine, University of Connecticut, Farmington, CT, USA supportive care. The journal Supportive Care in Cancer steadily increased its impact factor, and a Society News was circulated monthly to strengthen engagement with members.

The supportive care environment changed significantly. There was a paradigm shift from conventional cytotoxic therapy to biologically targeted therapies and immunotherapies which had a raft of new toxicities to manage and which often increased the financial stress on patients [2,3].

MASCC has restated its perspective of supportive care, but it is still patient-centred, evidence-based and encompassing physical, psychosocial and spiritual well-being from diagnosis, treatment and survivorship to end-of-life care. It is delivered by an interdisciplinary team of clinicians and allied health specialists. This promotes supportive care making excellent cancer care possible [4].

This history of the past 10 years was pieced together from interviews with 17 members who played significant roles in MASCC and supportive care over that time.

\section{Changes in supportive care in the past decade}

There was general agreement that supportive care in cancer as a focus for practice and research has become more prominent over the past decade. Partly, this is due to the need to manage 
the new side effects of the targeted therapies and immunotherapies, such as the checkpoint inhibitors [2]. However, there has also been more emphasis on addressing the psychosocial needs of patients which include financial toxicity highlighted by the development of newer high-cost anti-cancer treatments [3].

Supportive care of survivors has intensified as survival with stage IV disease increases [5]. Palliative care is also accepted as mainstream, which can contribute to the quality of life in dying patients and also improves quality of life when applied earlier. This was shown for patients randomised at diagnosis of metastatic non-small cell lung cancer to palliative care or standard oncological care, and this study also demonstrated improved survival [6].

The uptake of supportive care has not only been by doctors but also nurses and allied health professionals. Patients and their families have been a part of advocating for better supportive care and articulating their needs. MASCC has been a part of the spreading of supportive care internationally as new members participate in supportive care study groups, at scientific meetings and return home to low- and middle-income countries armed with new resources.

Advances over 10 years in specific supportive care topics were identified. Antiemetics to control chemotherapy-induced emesis further improved with trials of olanzapine in combinations improving the control of chemotherapy-induced nausea as well as vomiting [7]. The introduction of oral anticoagulants simplified the management of cancer-associated thromboembolic disease [8]. MASCC continued to produce mucositis guidelines and promote research into mucositis, and also, there are now new insights into the role of the microbiome and the gut-brain axis [9].

However, not all advances were pharmacological. The past decade saw the recognition that exercise was an important "prescription" for improving the wellbeing of cancer survivors, particularly with research in areas such as fatigue and anxiety and depression $[10,11]$.

The improvements in supportive care in cancer in the past decade have resulted from more researchers producing highquality research in this field.

\section{MASCC milestones in its third decade}

\section{Governance}

Jørn Herrstedt's term as President spanned the end of the second and beginning of MASCC's third decade (Table 1). There was a change in the governance of the organisation when he accepted Cindy Rittenberg's resignation and he and Dorothy Keefe, who was President-elect, interviewed Åge Schultz for the Executive Officer position. Jørn had known
Table 1 MASCC Presidents in the third decade

\begin{tabular}{ll}
\hline Years & President \\
\hline $2008-2010$ & Jørn Herrstedt, Denmark \\
$2010-2012$ & Dorothy Keefe, Australia \\
$2012-2013$ & Stephen Grunberg, USA \\
$2013-2014$ & Dorothy Keefe, Australia \\
$2014-2016$ & David Warr, Canada \\
$2016-2018$ & Ian Olver, Australia \\
$2018-2020$ & Rajesh Lalla, USA \\
\hline
\end{tabular}

Åge from his days working with ESMO (European Society for Medical Oncology), but Åge was new to MASCC.

A fresh perspective and experience of a larger society were partly the catalyst for the change in the Society which was built upon the solid basis of the founding group, which was to mark the third decade. Dorothy became the first woman to be President and being Australian, the first from outside the Europe/USA axis to hold the position. She continued a collegial style of leadership which had characterised Jørn's term as President.

One of the early tasks was to increase the economic viability of MASCC and Åge; Dorothy and the Board of Directors took it from a near deficit to a healthy reserve by the time $\AA$ ge retired in 2017. Åge with staff member Anne Young used a MASCC booth at a number of cancer meetings to engage as widely as possible with potential delegates, MASCC membership and partnership societies. It was also the era of transitioning into the digital world which increased the satisfaction and productivity of the small team of staff and contractors and made it easier to manage the organisation. MASCC benefitted from changing conference planning companies which improved the returns on the annual scientific meetings.

Dorothy and the Board developed a strategic plan which included strategies for growth of membership and opportunities for financial support beyond pharmaceutical company support of the meetings which had been the major source of income. Educational initiatives using the expertise of MASCC members were among the initiatives pursued.

When Dorothy's term ended, she was succeeded by Stephen Grunberg who had been a long-time contributor to MASCC and particularly to the antiemetic study group. He led enthusiastically but was only months into his term when he was diagnosed with the disease that he had spent his life treating and died in September 2013. Prior to that, MASCC Board members made a short video at the Berlin meeting to send to him and show him how sorely he was missed. Subsequently, the annual Stephen M Grunberg Memorial Award in recognition of scientific excellence was created. Many remember the amazing speech of Steve's contributions 
to MASCC that Richard Gralla gave at the inaugural award ceremony.

Dorothy stepped in to cover Stephen's absence and ended up completing his term. She presided over a gradual change in MASCC as more non-physician members joined. This included nurses, senior researchers and allied health disciplines, and she particularly encouraged young non-clinical researchers to become members, leading the way by closing her laboratory during the time of the annual meeting so that her young research colleagues could attend. That was an important feature of MASCC. You could contribute irrespective of your seniority or your discipline and could interact with leaders in the field in a congenial annual meeting environment irrespective of seniority.

David Warr was the next President. He had been a longstanding MASCC member and an important contributor to the antiemetic study group. A process of renewal was underway under David's leadership. A strategic planning meeting had taken place in 2014 in Amsterdam. Annual meeting committees became more centralised with meeting chairs and additional support provided to the chair to deliver a timely meeting program. David also emphasised the importance of engaging new members and MASCC began to offer an opportunity for new members to engage with existing members at the annual meeting to start building those connections and network within the MASCC family. MASCC continued to grow, and the 2015 Copenhagen meeting organised by Jørn Herrstedt had the largest attendance up until that time.

Ian Olver became President and presided over a time of tremendous change. Firstly, Åge retired and gave us a generous time to find his successor. Melissa Chin became the next Executive Director and had a very different skillset from those who had previously held the role. Her background had been in science augmented with strategy, business and operations as applied to healthcare. She had been working at the University Health Network and more specifically Princess Margaret Cancer Centre including a consulting project to build a toptier cancer centre in Qatar. David Warr had worked with her at Princess Margaret and was instrumental in making the connection.

The headquarters of MASCC moved from Copenhagen to Toronto, and although we retained Olexandra (Sasha) Stupak in Europe for his membership and information technology roles, the financial and legal advisors were changed, and we took the opportunity to modernise and simplify the Constitution. The Society News, with Toni Clark as editor, was no longer tied to being published in Supportive Care in Cancer and started to be circulated electronically on time, monthly. Ian commenced a column from the President to keep MASCC members updated about what decisions the Executive were considering, and Toni filled it with news and activities of members. It included pictures, in-depth articles, research highlights and reports of recent and upcoming supportive care conferences. It also became a source for social media content as the Communications Committee added the challenge of engaging in social media to their responsibilities, which became a major focus with Anna Boltong as Chair, increasing our presence and impressions and our understanding of social media best practices and analytics. The website was revamped under the guidance of Beth Hollen. This all served to better connect the MASCC family of members.

Soon after the Copenhagen meeting, Åge and Ian met with a facilitator to start organising a strategic planning meeting to be centred on the 2017 Washington meeting. A broad crosssection of members served on several groups to consider our strategic directions in terms of new initiatives, how to increase membership and create new income streams. Many strategic projects began to take shape with foundations laid for partnerships in Japan, South America and India, stimulating MASCC membership opportunities and the MASCC accreditation of supportive care units which will later evolve to the MASCC Designated Centres of Excellence during Ian's presidency. Raj Lalla joined as President-elect, so that the plan could be executed over two terms.

Raj Lalla took over as President at the Vienna meeting in 2018. As a dentist-scientist, he was the first MASCC President who was not a physician. He embarked upon an affiliate program whereby 6 national-level supportive care organisations became MASCC affiliates. This added over 530 members to MASCC and strengthened our international collaborations. A MASCC-Designated Centres of Excellence in Supportive Care in Cancer certification program was formed; thanks to efforts by Carla Ripamonti and others. Under Annie Young, the Membership Committee introduced new incentive programs to encourage the recruitment and engagement of new members. As a result of the affiliate program and the membership incentive programs, MASCC membership more than doubled to over 2100 members from over 70 countries.

A prominent feature of the decade has been the broadening of international reach of MASCC.

\section{International}

In the first 20 years, the annual meetings alternated between the USA and Europe. It was during Dorothy Keefe's presidency that she and Ian Olver raised the idea of moving outside of that axis and bring the meeting down to the Asia Pacific region, specifically to Australia. Initially, there was a concern about the financial risk that this would pose, but the concept was underpinned with a strategy to attract new members from countries in the region to counterbalance any reluctance for US and European members to travel further than usual.

In 2016, the MASCC/ISOO scientific meeting was held in Adelaide. The meeting was used to celebrate 25 years of MASCC meetings. It also made the transition into the $21 \mathrm{st}$ century by introducing e-poster sessions. Over 1070 
registrants from more than 50 countries attended. There was particularly strong support from Japan, Korea and China. Japan had just formed JASCC, the Japanese national supportive care organisation, and they have always invited MASCC members to present at their meetings. They also came to the next MASCC/ISOO meeting in Washington in large numbers and are now part of the affiliate program that Raj Lalla developed. Moreover, the MASCC meeting is due to be held in Japan in 2023. Currently, the MASCC affiliates are the French Association for Supportive care in Cancer (AFSOS), Portugal Association for Oncology Supportive Care Research (AICSO), Indian Association of Supportive Care in Cancer (IASCC), Japanese Association of Supportive Care in Cancer (JASCC), Italian Network of Supportive Care in Oncology (NICSO) and the Russian Society of Supportive Care in Oncology (RASSC).

This last decade has truly promoted the multinational nature of the Society.

\section{Study groups}

The study groups are the lifeblood of MASCC and drive the dissemination of the science and practice of supportive care (Table 2). The most significant impact worldwide has been from those groups who in over two decades have produced international guidelines, best exemplified by the evidencebased antiemetic, mucositis, neutropenia and oral care

Table 2 MASCC study groups

Study groups
Antiemetics
Bone and musculoskeletal
Digital health subgroup
Education
Fatigue
Geriatrics
Haemostasis
Immuno-oncology subgroup
Mucositis
Neurological complications
Neutropenia, infection and myelosuppression
Nutrition and cachexia
Oncodermatology
Oral care*
Pain subgroup
Palliative care
Paediatrics
Psychosocial
Survivorship

*The oral care study group is a study group of the International Society of Oral Oncology (ISOO) guidelines. These have been updated over the past decade, and external guidelines have been endorsed, such as the International Paediatric Fever and Neutropenia Guidelines, and new guidelines such as fatigue are in preparation. The study groups have also produced assessment tools such as the MASCC Antiemesis Tool (MAT), The MASCC Oral Agent Teaching Tool (MOATT) and the MASCC EGFR Inhibitor Skin Toxicity Tool (MESTT).

The study groups contribute practical workshops to the annual scientific meetings, often in the last decade, by collaborating with each other. Also, there has been an increased use of videoconferencing between face-to-face meetings to conduct study group projects over the year.

To address the issue of variable performance of the groups, performance indicators have been developed, but also, awards have been introduced for outstanding leadership and productivity of the groups. Over the decade despite a reluctance to discontinue groups, but as an example, the respiratory group was disbanded when interest waned. The Study Groups policy was updated to allow for the emergence of new subgroups in areas of emerging interest. Three such subgroups currently exist: immuno-oncology, cancer pain, and digital health. The expectations of groups were standardised, and study group leadership is term-limited to bring new leaders to the fore. The great strength of these groups is that young researchers can work with highly experienced senior members on projects with international impact.

\section{Publications}

The journal of MASCC, Supportive Care in Cancer, has only had two dedicated editors since 1993, and Fred Ashbury has held the role for all of the third decade, having been appointed in 2009. The journal has done much to promote supportive care and has steadily increased its impact factor. It has continued to evolve over the 10 years, having originally focused on the toxicities of systemic therapies to encompass subjects including psycho-oncology, financial toxicity, quality of life and communication issues and, most importantly, guidelines. It therefore has increased its appeal to the interdisciplinary supportive care community. As with most journals, publishing online prior to print allows early access, and yet, the journal still has a printed presence. Access to the journal is an important inducement for MASCC membership. Towards the end of the decade, several senior MASCC members published the MASCC perspective on the nature of supportive care in cancer in the journal [4].

MASCC published the MASCC Textbook of Supportive Care and Survivorship in 2011 and a second edition in 2018 with Ian Olver as Editor [12]. The second edition has 42 chapters and 91 contributing authors largely drawn from the MASCC membership which demonstrates the breadth and expertise of the organisation and its members, and this has 
been an additional resource on supportive cancer care and source of income for MASCC.

\section{Annual meetings}

MASCC annual scientific meetings have always included a strong scientific program of the worlds' leading experts in supportive care in cancer showcasing international learnings and collaboration. The MASCC annual meeting is held jointly with ISOO (Table 3). In this decade, MASCC transitioned from trying to find a local Scientific Meeting Chair to appointing a chair for a 2-year term. Most people, regardless of seniority, learn something new at a meeting. However, when we interviewed members about their most memorable meetings, they found it difficult to remember meetings by specific presentations. There was an appreciation of the larger meetings such as Copenhagen and New York due to the number of presentations and delegates with which to interact, and the collegial aspects of MASCC meetings were noted. The meeting shaped the careers of many emerging researchers, through the opportunities for mentorship and support, being invited into study groups by senior members and ignited or reignited enthusiasm for supportive care in others. It has been a valuable source of networking and developing leadership skills under the guidance of those members with international experience.

MASCC/ISOO meetings have often been a focus for lobbying local politicians for increasing supportive care in their countries, as exemplified by the 2009 meeting in Rome when Carla Ripamonti proposed to the Director General of the National Cancer Institute of Milan, and then Andrea Antonuzzo proposed to the Director in Pisa, to open a unit dedicated to supportive care, and now, there are units, doctors and nurses dedicated to supportive care. They also formed their own national society (NICSO), which is now an affiliate of MASCC.

Table 3 MASCC/ISOO scientific meetings in the third decade

\begin{tabular}{lll}
\hline Year & Scientific meeting chair & Destination \\
\hline 2010 & Patrick Stevenson-Moore & Vancouver \\
2011 & Kostas Syrigos and Ourania Nicolatou-Galitis & Athens \\
2012 & Richard Gralla & New York \\
2013 & Petra Feyer & Berlin \\
2014 & Declan Walsh & Miami \\
2015 & JØrn Herrstedt & Copenhagen \\
2016 & Dorothy Keefe and Ian Olver & Adelaide \\
2017 & Rachel Gibson & Washington \\
2018 & Rachel Gibson & Vienna \\
2019 & Andrew Davies & San Francisco \\
\hline
\end{tabular}

It reflects the nature of MASCC, though the networking and social events were what members emphasised. The interesting cities in which meetings were held encouraged many delegates to bring their families, and those from host cities often entertained the visiting delegates.

Many of those interviewed mentioned the dinners, such as when the previously restricted President's dinner was opened to general membership in Adelaide, and dancing included delegates crowding into a large Perspex cube used earlier by the entertainers at the dinner. Then, there was the magnificently grand venue in Vienna which was the ornate old Stock Exchange building, where a "MASCC-cuerade" Ball was enhanced by face painting, or the more hippy-like vibe of San Francisco captured by its photo booth.

The value of MASCC was eloquently expressed by those who remembered a meeting because they had become the President or won the Distinguished Service Award at that time, and they counted those events as their career highlights (Table 4).

\section{The future of MASCC}

There is a great confidence that MASCC will continue to grow and increase its influence over the next decade. As an interdisciplinary society, it will continue to diversify. It will continue to expand its guidelines, research tools and educational activates, and its affiliate relationships with national bodies will continue to expand, and it will act as an international umbrella organisation. The study groups must not be allowed to stagnate, and the organisation will have to increasingly embrace the digital world and recognise the changing needs of succeeding generations of members, while retaining its established expertise. MASCC must build its capacity within, in order to support its members and its mission to strengthen supportive care globally for worldwide patients who will benefit from the excellent cancer care that follows.
Table 4 MASCC Distinguished Service Award winners in the third decade

\begin{tabular}{ll}
\hline Year & DSA winner \\
\hline 2010 & Cynthia Rittenberg \\
2011 & Linda Elting \\
2012 & Paul Hesketh \\
2013 & Declan Walsh \\
2014 & Dorothy Keefe \\
2015 & JØrn Herrstedt \\
2016 & Matti Aapro \\
2017 & David Warr \\
2018 & Charles Loprinzi \\
2019 & Rachel Gibson \\
$2020 / 2021$ & Ian Olver \\
\hline
\end{tabular}


As Raj Lalla was succeeded by Andrew Davies to commence MASCC's 4th decade, the world was being heavily impacted by the COVID-19 pandemic. The 30th Anniversary celebrations planned for the year commencing with the meeting in Seville in Spain did not take place as the meeting was cancelled as the world locked down. However, as senior MASCC members recognised in an Editorial in Supportive Care in Cancer, many of the issues faced by patients with cancer were the psychosocial ramifications of COVID-19, and diverse integrated support mechanisms needed to be developed [13]. While such patients' needs persist, MASCC will weather the storm.

Acknowledgements In addition to the authors, we wish to acknowledge those who have provided permission and were interviewed as part of researching this MASCC History: Andrew Davies, Åge Schultz, Fred Ashbury, Toni Clark, David Warr, Dorothy Keefe, Rachel Gibson, Paul Hesketh, Carla Ripamonti, Fausto Roila, Andrea Antonuzzo, Paolo Bossi, Leslie Johnson and Beth Hollen.

Author contributions All authors whose names appear on the submission made substantial contributions to the conception of the work and the acquisition of data.

Drafted the work (Ian Olver) or revised it critically for important intellectual content (Melissa Chin, Rajesh Lalla)

All approved the version to be published and agree to be accountable for all aspects of the work in ensuring that questions related to the accuracy or integrity of any part of the work are appropriately investigated and resolved.

Data availability The source interviews will be kept for 15 years and can be made available by contacting the corresponding author.

\section{Compliance with ethical standards Not applicable.}

Conflict of interest Both Ian Olver and Rajesh Lalla have been past presidents of MASCC, and Melissa Chin is the current Executive Director.

No author has any other relevant financial or non-financial interests to disclose.

Consent to participate and publish All the interviewees volunteered to participate, and I have written consent from all of them to publish and acknowledge their contribution to the paper.

Code availability Not applicable.

\section{References}

1. Rittenberg CN, Johnson JL, Kuncio GM (2009) An oral history of MASCC, its origin and development from MASCC's beginnings to 2009. Support Care in Cancer 18:775-784

2. Rapoport BL, van Eden R, Sibaud V et al (2017) Supportive care for patients undergoing immunotherapy. Support Care Cancer 25: 3017-3030

3. Carrera PM, Olver I (2015) The financial hazard of personalised medicine and supportive care. 23:3390-3341

4. Olver I, Keefe D, Herrstedt J, Warr D, Roila F, Ripamonti CI (2020) Supportive care in cancer-a MASCC perspective. Support Care Cancer 28:3467-3475

5. Mollica MA, Mayer D, Oeffinger K et al (2020) Follow-up care for breast and colorectal cancer across the globe: survey findings from 27 countries. JCO Global Oncol 6:1394-1411

6. Temel JS, Greer JA, Muzikansky A, Gallagher ER, Admane S, Jackson VA, Dahlin CM, Blinderman CD, Jacobsen J, Pirl WF, Billings JA, Lynch TJ (2010) Early palliative care for patients with metastatic non-small-cell-lung cancer. N Engl J Med 363:733-742

7. Zhou J-G, Huang L, Jin S-H et al (2020) Olanzapine combined with 5-hydroxytryptamine type 3 receptor antagonist (5-HT3 RA) plus dexamethasone for prevention and treatment of chemotherapyinduced nausea and vomiting in high and moderate emetogenic chemotherapy: a systematic review and meta-analysis of randomised controlled trials. ESMO Open 5:e000621. https://doi. org/10.1136/esmoopen-2019-000621

8. Song AB, Rosovsky RP, Connors JM, Al-Samkari H (2019) Direct oral anticoagulants for treatment and prevention of venous thromboembolism in cancer patients. Vas Health Risk Manag 15:175186

9. Bajic JE, Johnston IN, Howarth GS, Hutchison MR (2018) From the bottom-up: chemotherapy and gut-brain axis dysregulation. Front Behav Neurosci 12:104. https://doi.org/10.3389/fnbeh.2018. 00104

10. Kelley GA, Kelley KS (2017) Exercise and cancer-related fatigue in adults: a systematic review of previous systematic reviews with meta-analysis. BMC Cancer 17:693. https://doi.org/10.1186/ s12885-017-3687-5

11. Craft LL, Vanlterson EH, Helenowski IB, Rademaker AW, Courneya KS (2012) Exercise effects on depressive symptoms in cancer survivors: a systematic review and meta-analysis. Cancer Epidemiol Biomarkers Prev 21:3-19

12. Olver I (ed) (2018) The MASCC textbook of cancer supportive care and survivorship $2^{\text {nd }}$ ed. Springer International Publishing AG, Switzerland

13. Young AM, Ashbury F, Schapira L, Scotté F, Ripamonti CI, Olver IN (2020) Uncertainty upon uncertainty: supportive care for cancer and COVID-19. Support Care Cancer 28:4001-4004

Publisher's note Springer Nature remains neutral with regard to jurisdictional claims in published maps and institutional affiliations. 